\title{
Chapter 3 \\ Fisheries: A Case Study of Baltic Sea Environmental Governance
}

\author{
Piet Sellke, Marion Dreyer, and Sebastian Linke
}

\begin{abstract}
This chapter analyses environmental governance through a case study of fisheries management in the Baltic Sea and investigates the problems, challenges and opportunities for improving sustainability in this sector. Fisheries management in the Baltic Sea is politically and culturally complex, institutionally fragmented and confronted with serious environmental problems, such as recent shifts in cod stocks. The central challenge is therefore to establish a regionally based, ecologically sustainable and socio-economically viable fisheries governance system for the Baltic Sea. Our analysis is focused on how past and current reform processes of fisheries management in the Baltic Sea have been able to move away from the pathdependent and highly ineffective management system linked to EU's Common Fisheries Policy towards new regional arrangements and procedures that address environmental problems in the Baltic on par with the social and economic challenges. We first describe existing governance structures for fisheries management in the Baltic Sea and their role in procedures of knowledge production, policy advice and decision-making. We then examine how the different governance actors (i.e. scientists, stakeholders, policymakers) address key issues such as the framing of the 'overfishing problem', the handling of uncertainty in the interactions of risk assessment and risk management and the role of stakeholder participation and communication. The chapter concludes by emphasising the need for an improved understanding of how scientific developments and connected uncertainty problems, policy constraints and stakeholder perspectives can be brought together for improving the biological, ecological and socio-economic sustainability of Baltic Sea fisheries governance.
\end{abstract}

Keywords EU fisheries management • Uncertainty • Stakeholder participation • Communication • Regionalisation

P. Sellke $(\bowtie) \bullet$ M. Dreyer

DIALOGIK, Lerchenstrasse 22, 70176 Stuttgart, Germany

e-mail: sellke@dialogik-expert.de; dreyer@dialogik-expert.de

S. Linke

Department of Philosophy, Linguistics and Theory of Science, University of Gothenburg,

Box 200, 40530 Göteborg, Sweden

e-mail: sebastian.linke@gu.se 


\subsection{Introduction}

One common resource that the nine countries bordering the Baltic Sea share is fish. The case study presented here deals explicitly with the 'risk of overfishing', which we define as the potentially adverse effects of fishing activities in terms of overexploitation and subsequent unsustainable development of these activities from an economic, ecological and social point of view. The acute problems of overexploitation in fisheries and their deteriorating effects on ecosystems and biodiversity as well as the resulting social and economic crisis have been addressed globally (e.g. McGoodwin 1990; Worm et al. 2009). In Europe these management failures are generally seen as a consequence of a nonworking governance framework for EU fisheries management (CEC 2009b ${ }^{1}$; Villasante 2011) which also holds true for the Baltic Sea (cf. Aps and Lassen 2010).

The main commercially exploited species in the Baltic Sea are cod, sprat, herring and salmon. Under the Common Fisheries Policy (CFP), which is the governing framework for fisheries management in the European Union, the main goal is to reduce the risk of overfishing and achieve a long-term sustainable exploitation of fish stocks. The CFP's objective is to maintain or restore fish stocks to levels that can produce the so-called maximum sustainable yield (MSY), which implies catching the largest possible proportion of a fish stock over an indefinite time period (Salomon et al. 2014). However, the use of the MSY concept in fisheries has been critiqued for not being sufficiently precise, both in terms of its conceptualisation in literature (e.g. Punt and Smith 2001) and its application in the daily practice of EU fisheries management (personal observations). When studying overfishing in the Baltic Sea, we cannot look at specific species in isolation, as the dynamics between different fish stocks (e.g. cod, sprat and herring) as prey-predator relationships form complex food-web relationships (Österblom et al. 2007).

One of the key challenges that fisheries governance in the Baltic Sea and elsewhere currently faces is a transition towards an ecosystem approach to fisheries management (EAFM), which takes multispecies considerations into account such as the implications of an increased cod stock on other fish stocks. The shift to such a management approach requires a substantive change in terms of the advice production system for fisheries management, which so far has mainly responded to the requirement of setting catch limits as so-called total allowable catches (TACs) and distributing fishing quotas amongst the Member States according to the principle of 'relative stability'. A crucial component of this TAC management system is an annual single-species approach (rather than a multispecies approach) which is difficult to reconcile with EAFM and, also, at a less complex level, with long-term, mixed fisheries management. The existence of this and other institutional impediments to the shift from an annual single fish stock management approach resulting from the TAC system to EAFM has been described as a situation of 'institutional

\footnotetext{
${ }^{1}$ Relevant publications before and after this are CEC (2001a, b, 2006, 2007, 2008, 2009b).
} 
inertia' (Wilson 2009: 93). This institutional inertia is the central concern of this chapter.

Besides the problems with the TAC management approach, our case study also deals with the shift towards results-based fisheries management and the role of marine regions, Member States and stakeholders in such outcome-oriented management systems. Results-based management has been intensively discussed in the context of the recent reform of CFP, finalised in 2013. The European Commission's 2009 Green Paper on CFP reform suggested an approach where strategic decisions on principles and standards should remain at Community level (CEC 2009b), whilst decisions relating to technical implementation be delegated to Member States ideally organising themselves at the level of marine regions such as the Baltic Sea region (CEC 2009a). However, it is still unclear how the concepts of results-based management and a shifting burden of proof will be implemented through a regional approach under the new post-2013 CFP (Linke and Jentoft 2013; Nielsen et al. 2015).

In Wilson's publication The Paradoxes of Transparency, Science and the Ecosystem Approach to Fisheries Management in Europe, he highlights the importance of changing future fisheries management (Wilson 2009). Results-based management is identified as a promising alternative to current regulatory processes, which are overcentralised and top-down: 'The CFP can in many ways be argued to take the form of a classical intergovernmentalist, state-centric command-andcontrol, top-down management system' (Hegland 2009: 8). The European Commission's Green Paper (CEC 2009b) also recognised that the current CFP takes a top-down approach and needs to give the fishing industry more incentives to behave responsibly. In Wilson's and other's views, a 'nested results-based system, organised around both sets of economic activities and geographical areas' (Wilson 2009: 276; cf. Raakjaer and Tatenhove 2014), is better suited for governing an unpredictable and complex system such as the Baltic Sea's fisheries and essential for the implementation of EAFM. The role of stakeholders in CFP over the last 15 years is the other important topic taken up in this chapter. In particular, we look at how two main structures for stakeholder interaction within CFP - the Advisory Committee on Fisheries and Aquaculture (ACFA), set up in 1971 and now replaced by several specialised advisory councils, and the more recent Regional Advisory Councils (RACs) - inform CFP. The key research questions dealt with in this chapter with respect to the governance changes described here are: How is uncertainty dealt with in the governance interactions between risk assessment and risk management (science and policy)? And how does communication between different actors address differences in the framing of the central issues in today's fisheries governance structures? These fundamental governance issues are analysed and discussed. Our case study does not however deal with how external factors such as climate change, eutrophication (e.g. hypoxic bottoms), environmental pollution, invasive species or spreading diseases might contribute to decreasing fish stocks. Although these external pressures do exist, we do not treat them as part of the 'risk of overfishing'. 


\subsubsection{Research Approach and Analytical Framework}

The case study on which this chapter is based was part of the RISKGOV project carried out from 2009 to 2011. The research team conducted 15 qualitative semistructured interviews between February and October 2010 with stakeholders and actors involved in EU and Baltic Sea fisheries management. Six of these actors were from the policy sector (EU and country specific), two from science, three from industry, three from non-governmental organisations (NGOs) and one from a supranational organisation (DG MARE). The research informing the analyses of this chapter is further complemented by findings from two more recent research projects undertaken between 2011 and 2015 as well as extensive document analyses and interviews with other key actors, particularly from the Baltic Sea RAC. Finally, it also involved participatory observations of meetings connected to the implementation of the 2013 CFP reform and the new regional Baltic Member States forum BALTFISH. However, the concrete effects of this most recent CFP reform have not been investigated empirically and are only partially integrated in this study.

Six main aspects have been especially relevant for this case study and serve as the analytical framework for our analyses:

- Framing: As with many decision-making processes in the area of risks and technology, the starting point of a governance process is making the implicit definitions of the current situation and of the current problem transparent. Different stakeholders often ascribe different meanings to the same term. Making these meanings explicit is referred to as 'framing' in the governance literature (cf. Renn 2008). In the context of this case study, we were interested in whether and how stakeholders have divergent views about the problem of overfishing and whether the term 'overfishing' is based on a shared understanding by different stakeholders.

- Governance structures: The qualitative analysis and interviews with policy experts, scientists, industry and non-governmental stakeholders aimed at detecting existing governance structures in the area, both overt and covert ones. This part of the study dealt explicitly with institutional issues and questions arising out of the debate on regionalisation as an asset or substitute to current governance structures.

- Interaction of science and management: Fisheries' and maritime management in general are dependent on knowledge about fish stocks and their interactions. Assessing fish stocks is a complex scientific task because cause-effect relationships are influenced by many intervening variables. For example, the development of a certain fish stock is not only related to fishing capacities and limits but also to the specific species' prey or predator (e.g. seals), maritime pollution, parasites and many other variables such as salinity, all of which are important in the Baltic Sea ecosystem. Within the EU fisheries governance structure, the task of resolving natural complexity is left to the scientists who give advice to management and decision-making bodies. The interaction of science and management is therefore of fundamental importance. How scientific advice is transferred 
to the management sphere and how the scientific sphere takes up demands from management are two crucial aspects to enable a sound governance process. A particular focus in this study is the shift to an ecosystem-based approach to management and resolving uncertainty in the data.

- Different kinds of incomplete knowledge in science and management: The knowledge about a risk can be classified in three distinct categories (cf. Sellke and Renn 2010): complexity, uncertainty and ambiguity. Complexity is the difficulty of establishing a cause-effect relationship, for example, due to intervening variables or the multiplicity of variables included in the assessment. Complexity is, therefore, a cognitive conflict, i.e. there is not enough knowledge on all influencing variables and thus more knowledge has to be generated. Uncertainty often results from unresolved complexity but is also an entity of its own. It suggests that we do not know what we do not know. The lack of knowledge about unexpected and unknown effects can be due to stochastic relationships, ignorance or system boundaries. In the case of uncertainty, an evaluative conflict is posed. The third category, ambiguity, refers to the fact that risk assessment results can be accepted by different stakeholders as being sound science and valid but can also be interpreted differently in terms of the hazardous effects the risk might have. Further, normative, religious or other ethical considerations might overrun a technical risk assessment, for example, if for some stakeholders, only one of the common three pillars of sustainability is of value. Ambiguity thus stands for normative conflicts. The effects of the different kinds of uncertainty in science and management and how they are dealt with in Baltic fisheries are addressed here.

- Communication with and amongst stakeholders: Previous research in different risk-related areas has shown that misunderstanding with regard to the framing of an issue often leads to a flawed communication process later on (cf. Renn 2008). Further, in risk governance processes, specific forms of communication are appropriate at a given time; thus, not all communication (and participation) efforts are suitable to all occasions. How actors communicate with each other, however, is of broader and more fundamental importance to the whole governance process. Besides formal communication structures between one institution and another, informal communication channels between stakeholders are of equal importance. The changing role of stakeholders' involvement in Baltic Sea fisheries governance is therefore discussed under this heading.

- Improvement opportunities for dealing with fishing: Which measures, structures and changes in the management and/or advice system are of importance to the interviewee from his/her specific angle? What recommendations could be developed from the views articulated? From the specific point of view of the respective interviewee, certain insights might be found that cannot be seen from an outsider's perspective. The research process is, therefore, open to ascertaining the interviewees' thoughts and experiences with regard to improving management.

The six aspects that we focus on are partly overlapping and are dealt with in this paper in the following manner. First we describe the governance structures of EU 
fisheries management with CFP (Sect. 3.2). This is relevant background information for the results section (Sect. 3.3). The section addresses the two key aspects of assessment-management interactions and stakeholder communication processes. We present the results of our analysis of the interactions between risk assessment and risk management (i.e. how data is collected, communicated and fed into the policy process). We also describe the results concerning communication with and amongst stakeholders including role framing, transparency and discourse play in the communication processes. The presentation of the results is followed by a discussion section (Sect. 3.4); the paper concludes with some thoughts and recommendations (Sect. 3.5).

\subsection{Governance Structures}

\subsubsection{The EU's Common Fisheries Policy}

Fisheries management is one of the few areas where Member States have given EU institutions full decision-making power. ${ }^{2}$ The exclusive right of the EU to manage fisheries is set forth in the Treaty of Lisbon (Article 2B), which states that the EU will have 'exclusive competence' over 'the conservation of marine biological resources under the common fisheries policy'. 3

After the enlargement of the EU in 2004, all Baltic coastal states except Russia are now members of the EU. Since then CFP, originally established in 1983, is regulating the EU's fisheries activities. Prior to 2004, the states bordering the Baltic Sea managed internationally relevant issues of Baltic Sea fisheries multilaterally via the International Baltic Sea Fisheries Commission (IBSFC). ${ }^{4}$ However, with EU enlargement IBSFC became redundant and ceased its activities on 31 December 2005. The two remaining parties, namely, the EU and Russia, arrange bilateral fisheries agreements, which are approved on behalf of the Community by Council Regulation (EC) No 439/2009 in 2009.

\footnotetext{
${ }^{2}$ Important regulations for the fisheries sector are EC No 2371/2002, EC 2004/585, EC 2187/2005, EC 1098/2007, EC 439/2009 and EC 1226/2009.

${ }^{3}$ European Union, Treaty of Lisbon Amending the Treaty on European Union and the Treaty Establishing the European Community, 13 December 2007, 2007/C 306/01, available at http:// www.refworld.org/docid/476258d32.html [accessed 7 July 2014].

${ }^{4}$ The IBSFC was established in 1974 on the basis of the Convention on Fishing and Conservation of Living Resources in the Baltic Sea and the Belts (the Gdansk Convention) signed by the Baltic countries in 1973.
} 


\subsubsection{The TAC System}

So-called total allowable catches (TACs) ${ }^{5}$ are the key management measure for fisheries under CFP. These TACs are allocated amongst the EU Member States as 'national fishing quotas' on the basis of the 'relative stability' principle (Symes 1997), which ensures Member States a fixed percentage share of fishing opportunities for commercial species by taking into account countries' historical catch records before joining CFP.

TACs and quotas $^{6}$ are annually allocated for all commercially important fish stocks of the Baltic Sea. The EU Council of Ministers takes final decisions regarding TACs and related measures. The Council receives a proposal from the EU Commission for the following year's TACs and the conditions under which they should be caught.

The EU Commission is informed by scientific advice from the International Council for the Exploration of the Sea (ICES) in order to prepare proposals for TACs and other regulations (cf. Hegland 2009). ICES is an intergovernmental scientific organisation founded in 1902 and brings together more than 1,600 marine scientists from 20 countries to coordinate and promote marine science and provide scientific advice to a set of clients in response to their requests (see www.ices.dk). The biggest client of ICES is the European Commission with most advice requests coming from DG MARE and some from DG Environment. The OSPAR and HELCOM Conventions are also amongst ICES's regular clients. With its permanent secretariat in Copenhagen, Denmark, the main part of ICES's work is carried out by more than 100 working groups, assigned to specific topics of research. Whilst analysis of the conditions of fish stocks remains the main job of ICES in the fisheries area, the scientific organisation tries to increasingly provide advice at ecosystem level to support the intended shift towards a more holistic approach to managing Europe's seas (cf. Stange et al. 2012).

Scientific advice from ICES is also received by and channelled through the European Commission's own Scientific, Technical and Economic Committee for Fisheries (STECF) which is made up of scientists and experts, particularly in the fields of marine biology, marine ecology, fisheries science, fishing gear technology and fishery economics. It is the task of STECF to review the assessment of ICES with regard to biological, ecological, technological and economic issues and to pass it on to the Commission's Directorate-General for Maritime Affairs and Fisheries (DG MARE).

DG MARE, in addition to obtaining the scientific advice from ICES and STECF's evaluation of it, also executes a consultation process, which includes receiving advice from two stakeholder structures, the Advisory Committee on Fisheries and

\footnotetext{
${ }^{5}$ Under EU law, TAC means the quantity that can be taken from a stock each year. After CFP reform in 2013 and its ban to discard fish at sea, TACs now refer to the actual catch rather than landings.

${ }^{6}$ Under EU law, 'quota' means a proportion of the TAC allocated to the Community, a Member State or a third country.
} 
Aquaculture (ACFA), which provides advice from industry to the Commission on fisheries issues, and the Regional Advisory Councils (RAC), created after the 2002 CFP reform and finally established between 2004 and 2008. ${ }^{7}$ Economic interests have been predominant in ACFA's structure, even more important than economic issues are to $\mathrm{RACs}^{8}$ (Wilson 2009: 96). ACFA, unlike RACs, mainly represents industry organisations at the European level.

The output of DG MARE is in the form of proposals to the EU Council of Ministers for decision-making. The most important of these decisions relate to setting the annual TACs for each species. Quotas of Member States, decided by the principle of 'relative stability', are thereupon distributed by national governments to their own operators who fish in national waters. However, although European Member States have given decision-making power to the EU, according to the principle of subsidiarity, they also carry responsibilities. Since the Treaty of Lisbon was signed in 2007, decision-making is shared between the EU Council of Ministers and the European Parliament although decisions on TACs still fall outside their joint purview.

\subsubsection{Towards a Regionalised Results-Based Management?}

Based on the principle of subsidiarity, it is up to the Member States as to how they distribute their quota allocation to their fishermen. It is also the responsibility of the Member States to pass the relevant laws and regulations and monitor and enforce compliance.

Under the pre-2013 CFP, there were a number of initiatives taken and elements for a regionalisation of the governance of risks pertaining to unsustainable fisheries:

- The CFP recognises the specificity of Europe's different seas and oceans by grouping technical measures into regional regulations. This included Council Regulation (EC) No 2187/2005 of 21 December 2005 for the conservation of fishery resources through technical measures in the Baltic Sea, the Belts and the Sound.

\footnotetext{
${ }^{7}$ Seven Regional Advisory Councils have been created since 2004 under CFP. Five are based on geographically and biologically coherent zones. Besides the Baltic Sea, other zones include the Mediterranean Sea, the North Sea, the Northwestern Waters and the Southwestern Waters. The two other RACs are based on the exploitation of certain stocks: pelagic stocks in Community waters (except in the Baltic and Mediterranean Seas) and high sea fisheries outside Community waters. With CFP reform in 2013, the name changed to merely Advisory Councils (AC), and three additional ones were set up for Aquaculture, Black Sea and distant fisheries (Hatchard and Gray 2014; Linke et al. 2014; Long 2010).

${ }^{8}$ The fisheries sector has been assigned a predominant position within RACs: in both the General Assembly and the Executive Committee, a majority (two thirds) of the seats are allotted to representatives of the fisheries sector and only one third to representatives of other interest groups (EC 2004, Art. 5(3)). This distribution of seats was changed in the 2013 CFP reform to a 60:40 representation ratio.
} 
- Under the 2002 CFP reform, a system of Regional Advisory Councils was established that included the Baltic Sea RAC. The RACs are a mainstay of the EU's revised CFP. They are meant to satisfy stakeholders' demands for better involvement and thereby reduce deficits in regulatory compliance and enforcement and enrich the decision-making process in the fisheries through the prioritising of stakeholders' knowledge and experience (Linke et al. 2011). Whilst the RACs mainly respond to EU and national policy proposals, they may also act on their own initiative by proposing ways for dealing with problems, which they feel need to be addressed. The Baltic Sea RAC, for instance, took initiative on the issue of deficits of control and enforcement in the Baltic cod fishery, by coming up with long-term management plans. It also convened a major conference in Copenhagen on control and compliance in the Baltic Sea in March 2007 at which a set of conclusions were drawn on how this major problem of deficits of control could be resolved (CEC 2009b).

In the wake of the 2013 reform of CFP, the regionalisation of fisheries management in the EU became more relevant and concrete (cf. Raakjær and Hegland 2012; Symes 2012), particularly in the case of the Baltic (Hegland et al. 2015). This regionalisation happened not only in fisheries management but also in other domains of EU marine governance (cf. Gilek and Kern 2015). Whilst CFP remains in charge of fisheries in the Baltic Sea, in 2009 a new council was formed amongst the region's Member States, the Baltic Sea Fisheries Forum (BALTFISH). BALTFISH was formalised in 2013 through a Memorandum of Understanding (MoU) between the eight EU Member States in the region (BALTFISH 2013) so as to enable cooperation on Baltic Sea fisheries management. It is empowered through delegated or implemented acts from the EU Commission (Council and Parliament 2013). As stated in Article 18(2) of the basic regulation, Member States of the region 'shall cooperate with one another in formulating joint recommendations' and 'consult the Advisory Councils' (ACs, the former RACs), whilst the Commission facilitates the possibility of other relevant scientific bodies contributing (ibid., 38). Due to the innovative and proactive approach established with BALTFISH, the Baltic fisheries context has been held up as a forerunner and role model by the previous Commissioner for Maritime Affairs and Fisheries, Maria Damanaki, for how regionalisation of fisheries management could be implemented across Europe.

\subsection{Insights into Risk Assessment-Risk Management Interaction and Stakeholder Communication Processes}

This section presents the results of our case study primarily based on qualitative interviews carried out with different actors in the context of Baltic Sea fisheries. First, Sect. 3.3.1 summarises the results of the interaction between the spheres of risk assessment (science) and risk management (policy). Thereafter, we present in Sect. 3.3.2 results on communication with and amongst stakeholders. 


\subsubsection{Interactions between Risk Assessment and Risk Management}

Interactions between the spheres of risk assessment and risk management are crucial for any successful risk governance process. Results from risk assessment have to be translated and transformed into manageable actions and decisions, a process that is often complicated by the complexity and uncertainty of the subject matter. A successful link between risk assessment and risk management is often based on transparent communication and open dialogue. Conversely, unsatisfactory risk management results are often due to communication and interaction problems between the two spheres. The following sections analyse the interaction processes between those two spheres in the context of fisheries' management in the Baltic Sea.

In general, our interviews addressed questions pertaining to decision-making structure for fisheries' management and, closely related to that, regionalisation. Regionalisation refers to changes in CFP's decision-making structure. Divergent views exist as to whether regional bodies should work merely consultatively or if they should also receive decision-making powers. These issues are important given the context of the new CFP reform process and its implementation (especially regarding the discard ban), which occurs at the regional level of the Baltic Sea through cooperation with and via BALTFISH. The new CFP reform process puts ACs potentially in a more responsible role and encourages them to contribute more proactively to management plans and increase coordination and collaboration with the Member States in the specific region. A failure of ACs and Member States to do so would result in the EU reverting back to traditional top-down management processes. Increased coordination would serve as an incentive for RACs and Member States to intensify their roles as mentioned, for example, at a Commission seminar on implementation of the CFP reform (http://ec.europa.eu/fisheries/news_and events/events/20131025/index_en.htm; cf. Linke and Bruckmeier 2015). The Baltic Sea is one area where CFP reform could be implemented because a cooperative Member State forum, namely, BALTFISH, already exists, which could facilitate integration and harmonisation of stakeholders.

All of our interviewed actors, regardless of their institutional affiliation, supported a stronger emphasis on regionalisation. However, different views existed on how far regionalisation should go, how it can and should be implemented and what the real objectives of this regionalisation process should be. In discussing the prospects for regionalising CFP, Symes (2012) fears the EU would be in legal limbo and hence the regionalisation process would end with 'a note of frustration', i.e. 'that regionalising the CFP will be decided on legal and procedural grounds rather than from a perspective of good governance and what is best for the fisheries' (Symes 2012, 19).

None of the interviewees from science, industry, policy-making or the NGO sectors wanted to transfer decision-making power to the regional level alone. Although many of the actors would like to see more decision-making power transferred to the regional level, the lack of any involvement of institutions at EU level was seen to be 
more disadvantageous than advantageous. The need for an overarching structure for a region that is by nature multinational and comprises an open resource was acknowledged by all actors.

The following five subsections describe the process and challenges of generating the necessary knowledge to be used for decision-making processes. Challenges arise at each step, beginning with data collection through analysis and management of uncertainty.

\subsubsection{Data Collection: The Analysis and Advice Process}

The starting point of giving good scientific advice to the policy sector is the data collection process. Good data collection depends on the robustness of data collection procedures. National Fisheries Institutes (NFIs) collect data through survey vessels with high costs attached to the process (Wilson 2009: 96). Besides fisheriesindependent data, fisheries-dependent data are also gathered, mainly through sampling of landings.

Inconsistencies between data collection across countries result in controversies about data gathered. This has been especially true with regard to discards of fish in relation to stocks. The heterogeneity of national authorities responsible for enforcement and inspection, as well as different scientific methodologies in relation to calculating the length or ageing of landings, also complicates comparisons. As Wilson (2009) describes, data from fisheries is often not regarded as reliable and conflicts around data sources seen to be politically laden. An example of the problems with unreliability highlights this. In 2004 it was estimated that landings of cod were under-reported by $35 \%$ (Wilson 2009: 99). However, scientists were heavily dependent on this data. Consequently, unreliable data have negative effects on ICES' analyses later on in the process which could result in unreliable assessments of fish stocks and then possibly poorly formulated recommendations.

The system of data gathering for fisheries has improved through means like video surveillance on trawlers and sophisticated enforcement procedures that help especially with discard data. This applies particularly in relation to the discard ban, which was first implemented in January 2015 in the Baltic Sea.

The advice process has a very formalised procedure. First, the client asks for advice. Then expert groups (coordinated by ICES) have to collect data which is used to draft a technical scientific report. The draft report is then peer-reviewed by independent experts, ${ }^{9}$ and the review as well as the draft report is used by the advice drafting group to give advice. This final 'ICES advice' is then agreed upon in the Advisory Committee (ACOM).

\footnotetext{
${ }^{9}$ This official external peer-review process was changed to an internal review in 2014.
} 


\subsubsection{Mitigation of a Basic Conflict Through Long-Term Planning}

In 2002, the EU's CFP underwent a substantial reform process aimed to ensure sustainable exploitation of living aquatic resources. This was a landmark shift in EU fisheries governance. Since then, the conceptual basis for fisheries management under CFP is the maximum sustainable yield (MSY) principle, the precautionary approach and the ecosystem approach to fisheries management (EAFM). Key elements of this reform include (EC 2002):

- The adherence to the precautionary approach to protect and conserve living aquatic resources and to minimise the impact of fishing activities on marine ecosystems

- Adoption of a more long-term approach to fisheries management involving the establishment of multi-annual recovery plans for stocks outside safe biological limits and of multi-annual management plans for others stocks

- Reduction of fishing effort as a fundamental tool in fisheries management, notably in the context of multi-annual recovery plans

- Aim to progressively implement an ecosystem-based approach to fisheries management

- Increased involvement of the fisheries industry and other groups affected by CFP through the creation of stakeholder-led Regional Advisory Councils

Interviewees suggested that the move to a long-term approach to fisheries management has mitigated (or has potential to mitigate) conflict around TAC levels between scientists and conservation groups on the one hand and fishers and managers on the other hand. This conflict arose because management decisions in the past usually were only 'moderately responsive to ICES advice in setting TACs' (Patterson and Résimont 2007). Generally, ICES advice is an answer to the question: 'How much fish can we take this year without running the risk of not having enough left over for long-term exploitation?' (cf. Wilson 2009: 10). Over the last two decades, as Wilson argues, the TAC finally decided upon by the Council of Ministers is close to but not as much as ICES has advised. According to scientists, conservation groups and also Commission staff interviewed, the TACs decided upon are not based on carefully weighted biological and social and economic considerations. Instead, they claim that the divergence is due to putting short-term economic and social interests before long-term ecological imperatives. Short-term decision-making along with poor enforcement is seen as the main cause for increased stock depletion risk and economic risks for fisheries and fishers, an issue exhaustively discussed in the scientific literature (cf. Aps and Lassen 2010; Villassante et al. 2011). Over the last 15 years, despite the growing importance of sustainable development, it is believed by many including the media that scientific advice has largely been ignored in European fisheries (Wilson 2009: 28). In recent years, however, there is some indication that TAC decisions by the Council of Ministers have been more in line with scientific advice. As a result, the percentage of European stocks considered as overfished has declined (Lassen 2009, p. 6; EC 2012). 


\subsubsection{New Challenges to Scientific Advice with an EAFM}

Long-term management approaches and EAFM in particular present huge, new challenges for scientific advice. Moving to these new forms of more holistic, ecosystem-based management will require substantial changes to processes within the scientific advisory system. This is currently high on the agenda in ICES and addressed, for example, through various new ecosystem working groups (e.g. WGIAB 2014; WKRISCO 2014). However, from the point of view of the managers in the European Commission, a historic gap has emerged that impedes management today, namely, between the form of advice that the scientific system is geared to provide and the form of advice that is progressively required under the revised CFP and EAFM context (Wilson 2009: 120). The shift towards long-term management is accompanied by a move towards management based on fleets and fisheries rather than single fish stocks. The move towards an EAFM is accompanied by a shift towards management of multispecies rather than single species. ${ }^{10}$ Notwithstanding these shifts, there are still many different views about what an EAFM approach should be about. EAFM is often referred to as a fisheries management policy, which addresses issues such as by-catch of marine mammals and birds and the impact of fishing on the sea bottom. However, fisheries scientists find it challenging to provide advice because they are primarily trained to deal with fish stock units and examine single species one by one. In other words, they are used to deliver advice on TAC and its imperative of setting and distributing fishing quotas (Wilson and Delaney 2005).

An EAFM, on the other hand, is meant to capture stakeholders' perspectives, as it is broad and all encompassing. Within the governance literature, EAMF-type processes are often called 'paralysis by analysis' (Renn 2008) because its overly inclusive nature may lead to inertia. Although the governance side of EAFM deals only with outcomes of the risk assessment, there are still doubts about the feasibility of EAFM. Scientific models used by ICES currently involve only a minor number of variables, partially because of a lack of data and also because a large number of intervening variables with stochastic relationships, natural variations and changed human behaviour become impossible at some point to calculate. Furthermore, fundamental problems arise with the framing of objectives aimed at protecting the ecosystem. Should the sea be treated like a farm that aims to address long-term food production or should it rather be protected for its own sake (cf. Wilson 2009: 170)? As Wilson points out, based on attitude surveys amongst scientists working for ICES, divergent world views have severe effects on specific management measures like the precautionary approach. He also noted that there was a significant difference between agency and non-agency scientists (Wilson 2009: 171).

NGO representatives that we interviewed favoured EAFM as an approach because it is a holistic perspective and basically deals with all variables that are important for integrated maritime management. They see it as an approach that

\footnotetext{
${ }^{10}$ In 2015, a new multispecies management plan for cod, herring and sprat in the Baltic Sea is to be adopted by the EU Parliament as has already been done by the Council of Ministers.
} 
overcomes the missing links between different biological, social and economic aspects concerning the Baltic Sea and that it improves communication. At the same time, they feel that more inclusive stakeholder processes should be launched and that regionalisation plays a crucial role in implementing EAFM. EAFM, however, also warrants the introduction of decision-making processes at the regional level. Some NGOs would like to see the inclusion of national decision makers into the current RAC structure.

Industry representatives interviewed in our study widely criticised EAFM, and if they did not, they saw it as a multispecies approach. Their criticism was based on the fact that EAFM was a tool by which different interest groups were able to get a voice on particular issues such as climate change or bird protection within the management system. Second, they said that the EAFM rather than being a tool for sectoral protection became a way to protect individual interests. Furthermore, even if EAFM was to be taken seriously, it would be impossible to implement because there were simply too many variables to include, many of which scientist have no knowledge about. In other words, EAFM is more of a utopian vision filled with flaws.

How the implementation of EAFM in EU fisheries and particularly in the Baltic Sea will develop is an issue left to further investigation. Recent scientific developments in ICES have been aimed at establishing so-called integrated ecosystem assessments (IEAs) as 'a formal synthesis tool to quantitatively analyse information on relevant natural and socio-economic factors, in relation to specified management objectives' (Möllmann et al. 2014). What remains to be seen is whether IEA development will succeed in becoming 'scientifically credible and socially legitimate' by integrating ecological, economic and social knowledge for marine governance in particular ecoregions (WKRISCO 2014).

Leading scientists from ICES that we interviewed have suggested that EAFM would be a significant challenge. In their view, it is next to impossible to connect multiple variables from different scientific disciplines and with different data methodologies into one model. The most that is possible in their view is a multispecies approach. However, regardless of their scepticism, ICES is preparing for EAFM through a working group.

Risk managers we interviewed had different views regarding EAFM. Some of them felt that EAFM will be the future of maritime management, whilst others shared the views of scientists. The differences in opinion largely stem from a different understanding of ecosystem-based management, i.e. whether it is aimed at the whole ecosystem or whether it targeted at a multispecies approach.

\subsubsection{Uncertainty as a Key Challenge}

Risk is a potential consequence (negative or positive) of human endeavour to obtain something they value (cf. Renn 2008). Risk assessment is the array of methods to assess hazards and vulnerability to these hazards. National experts working for ICES are in charge of assessing the vulnerability of the Baltic Sea and its fish stocks as well as the potential hazardous consequences of fishing in terms of discards. Risk 
assessment is always dependent on what we know about risk; in other words the task of risk assessment is to generate more knowledge about risk.

According to European Community legislation, CFP shall be guided by 'a decision-making process based on sound scientific advice which delivers timely results' (Council Regulation 2002, (Art. 2(2)b)). However, managers need to base their decisions on information which is associated with considerable scientific uncertainty $^{11}$ : There is uncertainty about how fish stocks will react to pressures, both human and environmental, and there is uncertainty involved in measuring existing fish stocks (due to sampling problems and misreporting of landings and discards) (Cochrane 2000; Finlayson 1994; Hawkins 2007). This type of uncertainty about size and age composition of fish stocks can result in incomplete knowledge that leads to ICES having difficulty making assessments. Consequently, giving advice to the Commission is also problematic. An example of this was the case of the Eastern Baltic cod stock in 2014 when an ICES assessment failed to provide adequate feedback on the present stock of cod (cf. Eero et al. 2015). The uncertainty challenge has therefore been and is still high on the agenda of both scientists and politicians, particularly because the TAC system in general has not been able to resolve the problems of overfishing and resource depletion (Lassen et al. 2014; Villasante et al. 2011).

CFP aims at responding to these perennial problems and growing insights vis-àvis ecological issues and recognises the need to adopt a precautionary approach and, progressively, to move from a single-species-based fisheries management towards EAFM (EC 2002; Howarth 2008). As the interconnectedness between fisheries and the environment is still imperfectly understood, assessors and managers are faced with an even greater uncertainty challenge when ecosystem considerations are taken seriously: 'We have to accept that uncertainty in the science inputs to management will be larger (and more realistic) in an EAF...' ${ }^{12}$ (Rice 2005: 269).

In summary, our case study interviews highlight that there is agreement amongst scientists and managers that EAFM requires an 'adaptive management' approach to deal with the complex and dynamic nature of ecosystems and the lack of full knowledge or understanding of how ecosystems function (cf. Linke and Bruckmeier 2015). The term 'adaptive management' is used to refer to a management approach that contains elements of learning-by-doing or research feedback, which make it possible to respond to such uncertainties (CEC 2008: 7f.).

\subsubsection{Disagreement About Uncertainty Characterisation}

ICES is in charge of generating knowledge about fish stocks for risk assessment. The process of how the necessary knowledge is created to assess further measures regarding fish stocks has been described above. Whilst ICES tries to gather the best available knowledge, issues of complexity cannot be addressed well within the

\footnotetext{
${ }^{11}$ Additionally, there is considerable complexity in defining cause-effect relationships.

${ }^{12}$ EAF means ecosystem-based approach to fisheries.
} 
current system. Any scientific analysis is only as good as the data used, and data on fish stocks gathered by survey vessels and partially validated by fisheries' data is often unreliable and always incomplete. Further, ecosystems such as maritime environments are a dynamic entity with stochastic effects and uncertain dynamics.

There are increasing calls for improved concepts of uncertainty treatment and improved methodology in the characterisation, consideration, communication and management of uncertainty for scientific assessment and advice. It has been argued, for example, by Dankel et al. (2012), that a better understanding of how to characterise scientific uncertainty and its implications are needed. However, according to our interviewees, the underlying problem has still not been resolved, namely, that DG MARE wants numbers, whilst ICES's scientists prefer to give more qualitative and nuanced information.

This poses a fundamental problem for the whole management process: ICES is expected to deliver recommendations as sound and clear as possible in order for DG MARE to draft proposals for action. ICES' advice, on the other hand, has to be legitimate and definitive, i.e. it cannot be open to different interpretations by different stakeholders (Wilson 2009: 124). That there is uncertainty, however, has to be somehow communicated for the advice to become credible, but how exactly uncertainty should and can be communicated to DG MARE is an ongoing discussion, not least because of different understandings of uncertainty between ICES and DG MARE. This is referred to as 'institutional uncertainty' (Linke et al. 2014).

Industry representatives in all countries generally felt more comfortable with management decisions made by the Council of Ministers, partly because the latter did not fully follow the advice of ICES. Industrialists felt that NGOs read ICES' advice all too literally. They on the other hand understood the uncertainties involved and thus expected decision makers to set different TACs than those of ICES. Unsurprisingly, NGO representatives were very much in favour of the precautionary approach to scientific uncertainties. They felt that given the lack of or the unreliability of data, the precautionary approach would better address concerns of sustainable management of resources. Representatives from ICES on the other hand were less perturbed. They saw themselves as delivering a service to DG MARE based on the available resources and knowledge. In their view, their assessment was mainly a biological-economic one. They did not see a threat of species extinction. Rather, they were concerned that if TACs were set too high, economic problems might arise. DG MARE representatives saw the problem similarly and referred mainly to the challenges of data reliability and communication of uncertainty. Further, they felt that local and anecdotal knowledge about fish stocks should be taken seriously.

\subsubsection{Stakeholder Communication Processes}

Communication amongst stakeholders, but also between stakeholders and institutions managing maritime affairs in the Baltic Sea, is a crucial element of the whole governance process. Failed communication as a result of certain stakeholders being 
excluded or poor framing of issues can lead to the rejection of assessment results, advice, recommendations and/or management decisions. It is therefore important to consider both formal communication channels and informal ones. The former add legitimacy to governance processes, whilst the latter have the potential to build trust and cross-sector coalitions for collaboration in management (cf. Linke and Jentoft 2013).

Even before communication on a specific issue begins, the framing of the issue is critically important. Whether something is seen as an opportunity or a risk or a threat or a challenge or should be looked at in terms of its economic, ecological or social effects or at all of them simultaneously determines subsequent communication processes.

\title{
3.3.2.1 Framing: The Issue of 'Overfishing'
}

Results from the interviews carried out suggest that there are highly divergent meanings attached to the term 'overfishing' by the main actors involved in European fisheries governance which consequently result in conflict amongst the actors. Today the EU Commission uses the term 'overfished' whilst addressing concept of maximum sustainable yield (MSY). The 2009 Green Paper says:

\begin{abstract}
While a few EU fleets are profitable with no public support, most of Europe's fishing fleets are either running losses or returning low profits. Overall poor performance is due to chronic overcapacity of which overfishing is both a cause and a consequence: fleets have the power to fish much more than can safely be removed without jeopardising the future productivity of stocks. (CEC 2009a: 7)
\end{abstract}

The Fisheries Secretariat ${ }^{13}$ states hereupon:

In 2009 the Eastern cod stock was described as being overfished with respect to the potential long term yield for the fishery, meaning that the stock could be much larger and more fish could be caught in the future if fishing mortality was reduced.

The Green Paper's statement ' $88 \%$ of Community stocks are being fished beyond MSY' therefore does not mean that these stocks are near to collapse but 'that these fish populations could increase and generate more economic output if they were left for only a few years under less fishing pressure' (CEC 2009a: 7). The concept 'outside safe biological limits' on the other hand refers to the more serious situation of overfishing, implying that these stocks 'may not be able to replenish' (ibid.).

Some interviewees said that conservation and environmental groups collapse the distinction between 'overfished stocks' and stocks near to collapse something that the media also does. According to many industry representatives and even other stakeholders, treating everything as overfished stocks is overdramatic and a case of

\footnotetext{
${ }^{13}$ Information from the website of The Fisheries Secretariat, which describes itself as 'a non-profit organisation dedicated to work towards more sustainable fisheries at an international level, with a focus on the European Union', http://www.fishsec.org/article.asp?CategoryID=1\&ContextID=194
} 
false information being fed to consumers and the wider public. If the resulting misconceptions were to influence consumer behaviour, this could have negative effects for the fishing and processing industries.

Official statements by the EU, of the type given above, can be used by different stakeholders to make different points. Whilst industry representatives we spoke to felt that the EU was not saying anything about biological extinction of species, NGO representatives felt that the EU was stressing that overfishing was taking place although they did not clearly define overfishing. A fundamental problem with regard to the framing of the issue of 'overfishing' is that it can be defined economically, socially or environmentally. Actors largely choose perspectives that best fit their own agendas. Our interviews revealed that differences in the framing of the issue of overfishing were not so much about whether species are close to extinction but rather about whether a long-term or short-term perspective with regard to overfishing should and could be addressed by EAFM.

As this analysis illustrates, framing does not only relate to what is understood by different actors about the issues at stake but also to what rules, procedures and conventions specifically mean in dealing with risk. EAFM is a remarkable example of this phenomenon since different actors point out different aspects of EAFM. It is understood by some actors as merely a multispecies approach, whereas others employ a more holistic view of the whole environmental system. These differences in the framing of the concept of EAFM need to be communicated within the governance process. If communication is poor, actors might not be talking about the same issue when they refer to EAFM. Further, if the framing differs, the interpretation of rules, procedures and conventions will differ as well.

\subsubsection{Enhancing Transparency in the Scientific Advisory System}

In the context of recent restructuring of ICES, participation has been extended by opening up meetings to 'observers' much more than in the past (cf. Stange et al. 2012). Since 2004, ICES has been inviting representatives from industry and environmental NGOs to attend meetings of the Advisory Committee on Fishery Management (ACOM) (Wilson 2009: 122), which has representatives from each of the 20 ICES member countries and meets every year in the spring and autumn. This 'transparency through observers' (ibid., p. 274) was a response to demands from both DG MARE and stakeholder groups.

In 2013, the Working Group on Maritime Systems (WGMARS) put forward their suggestions on how to shape a more transparent process that also integrates stakeholders in the scientific advice process. Specifically, the report emphasised the need to encompass stakeholders' research needs over the medium and long term, evaluate and propose best practices in stakeholder engagement in EU-funded projects and define terms of reference for an ongoing dialogue with stakeholders and scientists (ICES WGMARS Report 2013).

Generally, most of our interviewees valued increased transparency about procedures pertaining to generating scientific knowledge and advice and stressed the 
need for ICES to adapt to new societal circumstances. In recent years ICES has therefore undertaken substantial efforts to make its scientific advisory processes more transparent, reliable and digestible for non-scientists. For example, since 2013 ICES produces an 'up-to-date and easy-to-read digest of the official ICES advice', which is a popularised version of official communications that are more understandable to a wider audience. Distributed as an online paper (see, http://www.ices.dk/ publications/our-publications/Pages/Popular-advice.aspx) through, for example, social media, this popular advice presents ICES' new orientation towards nonscientific audiences. Whilst such initiatives are generally lauded amongst stakeholders and the general public, managers, for example, from DG MARE, feel that there is a need to discuss how to combine highly technical communications of scientific procedures 'at the bench' with more understandable communiqués for outreach.

\subsubsection{Risk Communication to the Public}

Industry and management representatives as well as scientists from ICES confirmed to us that 'overfishing' is a hot topic for the media. That fish stocks will be extinct e.g. by 2048 (cf. Stokstad 2009) is a good headline, but for industry representatives and managers, such headlines strain the governance process because it potentially exaggerates things. Hence, communication to the public should be through a shared framing process in terms of how the issue is framed.

Overall our interviewees did not see a need for more specific public participation within the governance process. Communication with the public was regarded as important in terms of sharing information. Although all interviewees agreed that it is always good to have the public involved (because of the complexity of the governance process), they did not feel that the public should make recommendations about future policies. Some of the interviewees, especially from DG MARE, saw the European Parliament as well as national parliaments as being the democratically elected representatives of the public.

\subsection{Discussion}

Our case study about Baltic Sea fisheries points out several problematic issues pertaining to a good governance process for fisheries management. Some of those issues are generic to the field of fisheries management itself, whilst others relate to organisational shortcomings which can be improved upon. Before making recommendations for such improvements, two basic issues need to be emphasised to point out key problematic areas:

1. Dealing with uncertainty in assessment-management interactions

2. Communication and stakeholder participation 


\subsubsection{Dealing with Uncertainty in Assessment-Management Interactions}

Estimates of fish stocks in the Baltic Sea, as well as elsewhere, have to deal with complex cause-effect relationships involving many intervening variables. The risk governance literature, which deals with complexities between cause and effect relations, calls for the best available involvement of experts in order to achieve prudent assessment results (Renn 2008). With regard to EU fisheries governance structures, ICES takes up this task by devoting all its efforts to involve the best available (natural) scientific expertise in order to advice decision makers in a way that minimises cognitive conflicts.

Uncertainty complicates complex governance arrangements of risk assessmentrisk management interactions in fisheries. Uncertainty is a major issue in the science-policy interface of EU fisheries management under CFP (cf. Dankel et al. 2012) and, as our results revealed, exists in several ways:

(a) Uncertainty in data gathering

(b) Uncertainty in data analysis

(c) Uncertainty impacts stemming from points $(a)$ and (b) in framing, evaluation and management

The fishery sector is characterised by the so-called second-order uncertainty (Renn 2008), i.e. a risk situation where circumstances might change in an unpredictable and unsystematic manner as in the case of fish stocks and the environmental system of which they are part. Second-order uncertainty is difficult to communicate, hence, our focus on it. In the case of biological assessments of fish stocks, it is helpful to make a distinction between aleatory and epistemic uncertainty (Renn 2008: 71). Aleatory uncertainty characterises randomness in samples, which means that only in the long run and with a large enough sample can the distribution of possible values be identified. Epistemic uncertainty on the other hand stems from a lack of knowledge of dynamics or phenomena within the field. Although extended data gathering and research might decrease both aleatory and epistemic uncertainties, with dynamic systems such as marine environments, uncertainty often prevails and can even increase as a consequence of further research as it happened in 2014 with the failure of ICES' Eastern Baltic cod assessment (Eero et al. 2015).

Distinguishing between the two types of uncertainty and designing communication processes that make the distinction between the two obvious to the ICES audience (the audience being broader than the clients alone) will increase transparency about different aspects of uncertainty and their role in assessment-management interactions. Such transparency about the type of uncertainty is especially needed as uncertainty is always interpretable, i.e. a subject of 'interpretative flexibility' (Meyer and Schulz-Schaeffer 2006), and therefore always a potential source of conflict in discussions amongst stakeholders in Baltic Sea fisheries. This is most notable in the Baltic RAC, where NGOs and fisheries representatives read different things from the scientific reports of ICES (cf. Linke et al. 2011, 2014). 
Biological assessments of fish stocks, particularly when applying EAFM, also have to deal with epistemic uncertainty. The conflict around epistemic uncertainty and how to interpret results cannot only be solved by further scientific analysis, as it is not merely a cognitive but also an evaluative conflict. At present the situation in EU fisheries governance leaves this question somewhat open. It is not clear as to who will discuss the implications of evaluative judgements that have to be made. The ways in which social aspects of uncertainty are currently addressed may play a crucial and yet underrated role in the further framing of EU fisheries management discourse, for example, with respect to contributions of BS RAC to the Baltic salmon management plan (Linke and Jentoft 2014). Further, a second field of conflict exists in terms of the interaction of science and management with the TACbased management system: policy and decision makers require numbers (quota advice) as input for further decision-making and communication, whereas the system of science or scientists would produce more qualitatively driven information. Uncertainty can also stem from unreliable and in some cases invalid data. Data analysis is obviously dependent on sound data gathering procedures. Unfortunately, data gathering is one of the problematic aspects of the process. This is partly due to logistical and practical restrictions and partly to differing interests of national NFIs and fisheries, who are mainly in charge of data gathering (Wilson 2009). The more unreliable the data gathering process is, the more unreliable data analysis and advice based on it. NFIs certainly have national interests and are closely connected to the national management and policy sector with Member States being part of the European Council. Hence, whilst data gathering methods have improved, they still account for a degree of uncertainty.

How the role of uncertainty in management and decision-making is conceptualised and dealt with has in turn also impacted the framing of the problem, risk evaluation, risk management and risk communication. Different framing perspectives in terms of what role uncertainty actually plays in risk management can lead to different interpretations of assessment results, which subsequently has consequences in terms of different risk evaluations and management strategies (e.g. applying the precautionary principle or not).

\subsubsection{Communication and Stakeholder Participation}

Communication amongst actors, and particularly with and amongst stakeholders, plays a central role in any governance process. Communication processes in EU fisheries management have improved significantly over the last two decades, particularly through RACs, increased interaction between scientists and stakeholders (e.g. in the form of observer status being given to RAC members at ICES meetings and vice versa), and management bodies improving communication. Further, participation in planning and decision-making processes has increased significantly in regional decision-making processes as, for example, with the discard ban, to be implemented in line with Article 15 in the new CFP reform (Council \& Parliament 
2013, 35). Both CFP reform and the new multispecies plan to be finalised in 2015 offer possibilities of the new interactions between the regional triangle of Member States (via BALTFISH), the stakeholder sector (via the BS RAC) and the EU Commission and hence offer both challenges and new opportunities for improved communication between these new management bodies.

The problematic aspects mentioned with respect to uncertainty treatment also come from inadequate communication. One example is the BS RAC: although it is a forum for opposing views to come together (i.e. NGOs and industry), communication is hindered by the uneven representation ratio of the two parties in the BS RAC and also poor material resources for working effectively on the questions at stake. Further, because of different normative assumptions (e.g. long-term versus shortterm value perspectives), uncertainty is interpreted differently by different actors and often cannot be reconciled (Linke et al. 2011; cf. Renn 2008).

Finally, communication is central to the interaction between scientists and management. Communication needs to be a two-way process in which mutual trust is built between actors. The goal should be to assist stakeholders in understanding risk managers' decisions and the rationale of risk assessment results (Renn 2008) so as to enable them to make informed choices in relation to their interests and values (Johannesen and Lassen 2014). To achieve these objectives, risk communication is a task for professionals, something which is rarely understood. Trust can be built if there is a willingness to admit that uncertainty exists in risk assessment results. Trust will also lead to legitimacy (Dankel et al. 2012; Renn 2008). We have illustrated based on our interviews that communication processes in the Baltic Sea fisheries sector are often lacking because trust is missing. Whether the new structures that have emerged after the 2013 CFP reform will improve mutual trust remains to be seen.

\subsection{Conclusions and Recommendations}

We have suggested in this chapter that the main challenges of fisheries governance in the Baltic Sea relate to risk assessment-risk management interactions and their treatment, communication of different forms of uncertainty, harmonisation of the (interdisciplinary) knowledge base and the organisation of stakeholder participation to improve communication. Based on our case studies, we conclude that current governance structures are not yet capable of fully addressing the problems of scientific uncertainty, interpretations of this uncertainty and connected misunderstandings amongst the different actors in terms of reaching desired outcomes of sustainable fisheries in the Baltic Sea. Increased interactions amongst individual actors, for example, in RACs as well as between different management organisations (e.g. ICES, RAC and the EU Commission), as well as more developed institutional and procedural designs for stakeholder involvement in management and decision-making at the regional level, are urgently needed for improving environmental governance of the Baltic Sea. 
EAFM, whilst placing further demands on fisheries science and management and their interactions, is an important step towards a more holistic, regionalised and stakeholder inclusive fisheries governance approach for the Baltic Sea that could help balance environmental and social dimensions. However, whilst the theory behind EAFM with its novel knowledge requirements with regard to integrated pressures, ecosystem impacts and societal concerns is rather well developed (cf. Gilek et al. 2015; McLeod and Leslie 2009), a coherent strategy for EAFM implementation is still lacking. Expectations rest with science, especially all of ICES' ecosystem working groups (e.g. the ICES/HELCOM Working Group on Integrated Assessments of the Baltic Sea, WGIAB), to put forward new tools and methods to build a knowledge base that can achieve integration that EAFM demands (cf. Möllmann et al. 2014).

Furthermore, the EU's CFP reform process 'opened up' EU fisheries governance in the Baltic Sea context to an extended regionalisation approach. Such an approach has been strengthened due to the new Member States collaborating via BALTFISH. Other reasons for this strengthening include increased incorporation of EAFM in the new CFP as well as integration and empowerment of the stakeholder sector due to a slightly enhanced role for the reformed RACs (ACs). Whilst stakeholders' input to the EU authorities via ACs still remains purely advisory, as it was during the previous CFP period, under the new basic regulation, both the Commission and the Member States are legally bound to respond with detailed reasons in cases where adopted measures or regulations diverge from the recommendations and suggestions that were received from the ACs (Council and Parliament 2013, Article 44, p. 47). However, the new provisions flagged under efforts of 'regionalisation' of the new (post-2013) CFP still remain relatively weak in EU's fisheries governance (Hatchard and Gray 2014; Salomon et al. 2014).

Overall, as Symes $(2012,1)$ states, the current CFP of the new regionalisation approach 'presently faces the most important challenge of its thirty year history'. The challenge is ensuring that the short-term management approach of annual fishing quotas is changed and a new perspective embracing more fundamental changes aimed at long-term viability and sustainability of the fisheries sector adopted. Such an approach should remain true to the overall European project (ibid.). Symes and other scholars, whilst discussing these new challenges, are pessimistic about whether the authorities in 'technocratic Brussels' (Salomon et al. 2014, 81) are willing to delegate powers to the regional levels such as the Baltic Sea.

However, despite such legal constraints, the Baltic Sea is seen as the closest prototype for regional cooperation under the post-2013 CFP (cf. Hegland et al. 2015). The future will tell if and how the new regionalisation project for fisheries governance in the Baltic Sea including BALTFISH will result in the implementation of EAFM and a stakeholder inclusive management approach.

In summary our recommendations for improving environmental governance of the Baltic Sea fisheries relate first of all to knowledge aspects, which are of paramount importance for CFP in general and hence also for the Baltic Sea context. Interdisciplinary knowledge and specifically social science research are the need of the hour (Linke and Jentoft 2014; cf. Urquardt et al. 2014) and therefore have to be 
better integrated into the risk governance cycle of fisheries management under CFP. An increased emphasis on social aspects promises to create the necessary trust between actors and also to take local knowledge into account. Furthermore, communication processes need to focus more on two-way channels of communication rather than only on providing information and educating people. Taking into account the social, cultural and economic needs of different stakeholders around the Baltic Sea will be crucial for communicating management results more appropriately to stakeholders. Ultimately, better results depend on better sharing of management responsibility amongst actors, both with respect to the aims of the newly reformed CPF and regional fisheries management in the Baltic Sea. The current CFP with its interest-based system of stakeholder representation (Linke and Jentoft 2014) and its legally bound centralisation of decision-making seems to leave little room for such visionary objectives of shifting the burden of proof and creating a more responsible, results-based management system (cf. Linke and Jentoft 2013; Nielsen et al. 2015). Any serious implementation of recommendations put forth above is still lacking in the Baltic fisheries context at the time of writing.

Acknowledgements The research was funded by the Foundation for Baltic and East European Studies and the European Community's Seventh Framework Programme (2007-2013) under grant agreement No 217246 made with the joint Baltic Sea research and development programme BONUS, as well as by the German Federal Ministry of Education and Research (BMBF) and the Swedish Research Council FORMAS. SL also acknowledges funding from the Swedish Research Council and Riksbankens Jubileumsfond. We wish to thank all these institutions for enabling this research. Two peer reviewers are also thanked for valuable comments on an earlier version of the chapter.

Open Access This chapter is distributed under the terms of the Creative Commons AttributionNoncommercial 2.5 License (http://creativecommons.org/licenses/by-nc/2.5/) which permits any noncommercial use, distribution, and reproduction in any medium, provided the original author(s) and source are credited.

The images or other third party material in this chapter are included in the work's Creative Commons license, unless indicated otherwise in the credit line; if such material is not included in the work's Creative Commons license and the respective action is not permitted by statutory regulation, users will need to obtain permission from the license holder to duplicate, adapt or reproduce the material.

\section{References}

Aps R, Lassen H (2010) Recovery of depleted Baltic Sea fish stock: a review. ICES J Mar Sci 67:1856-1860

BALTFISH (2013) Memorandum of understanding: principles and working methods of the Baltic Sea Fisheries Forum (BALTFISH)

CEC (Commission of the European Communities) (2001a) Green paper on the future of the Common Fisheries Policy. COM(2001) 135 final, Brussels, 20 Mar 2001

CEC (Commission of the European Communities) (2001b) European governance. A white paper, COM 428 Final. Brussels 25 Jul 2001 
CEC (Commission of the European Communities) (2006) Communication from the Commission to the Council and the European Parliament. Implementing sustainability in EU fisheries through maximum sustainable yield. COM(2006) 360 final. Brussels, 4 Jul 2006

CEC (Commission of the European Communities) (2007) Communication from the Commission to the Council. Fishing opportunities for 2008. Policy statement from the European Commission. COM(2007) 295 Final. Brussels, 6 June 2007

CEC (Commission of the European Communities) (2008) Communication from the Commission to the Council and the European Parliament. The role of the CFP in implementing an ecosystem approach to marine management. COM(2008) 187 Final. Brussels, 11 Apr 2008

CEC (Commission of the European Communities) (2009a) The Common Fisheries Policy. A user's guide. Office for Official Publications of the European Communities, Luxembourg

CEC (Commission of the European Communities) (2009b) Green paper. Reform of the Common Fisheries Policy. COM(2009) 163 final. Brussels, 22 April 2009

Cochrane KL (2000) Reconciling sustainability, economic efficiency and equity in fisheries: the one that got away? Fish Fish 1(1):3-21

Council \& Parliament (2013) Regulation 1380/2013 of the European Parliament and of the Council of 11 December 2013 on the Common Fisheries Policy

Council Regulation (EC) No 1098/2007 of 18 September 2007 establishing a multiannual plan for the cod stocks in the Baltic Sea and the fisheries exploiting those stocks, amending Regulation (EEC) No 2847/93 and repealing Regulation (EC) No 779/97. OJ of the European Union L 248/1, 22.9.2007

Council Regulation (EC) No 1226/2009 of 20 November 2009 fixing the fishing opportunities and associated conditions for certain fish stocks and groups of fish stocks applicable in the Baltic Sea for 2010. OJ of the European Union, L 330/1, 16.12.2009

Council Regulation (EC) No 2002. No. 2371/2002 on the conservation and sustainable exploitation of fisheries resources under the Common Fisheries Policy

Council Regulation (EC) No 2004/585/EC of 19 July 2004 establishing Regional Advisory Councils under the Common Fisheries Policy

Council Regulation (EC) No 2187/2005 of 21 December 2005 for the conservation of fishery resources through technical measures in the Baltic Sea, the Belts and the Sound, amending Regulation (EC) No 1434/98 and repealing Regulation (EC) No 88/98. OJ of the European Union, L 349/1, 31.12.2005

Council Regulation (EC) No 439/2009 of 23 March 2009 concerning the conclusion of the agreement between the European Community and the Government of the Russian Federation on cooperation in fisheries and the conversation of the living marine resources in the Baltic Sea. OJ of the European Union, L 129/1, 28.5.2009

Dankel DJ, Aps R, Padda G, Röckmann C, Sluijs JP, Wilson D, Degnbol P (2012) Advice under uncertainty in the marine system. ICES J Mar Sci 69(1):3-7

Eero et al (2015) Eastern Baltic cod in distress: biological changes and challenges for stock assessments. ICES J Mar Sci. doi:10.1093/icesjms/fsv109

European Commission (EC) (2012) Communication from the Commission to the Council concerning a consultation on fishing opportunities for 2013. COM 278 final

Finlayson AC (1994) Fishing for truth. A sociological analysis of northern cod stock assessments from 1977-1990. Institute of Social and Economic Research of Memorial University of Newfoundland, Newfoundland

Gilek M, Kern K (eds) (2015) Governing Europe's marine environment. Europeanization of regional seas or regionalization of EU policies? Ashgate, Farnham

Gilek M, Karlsson M, Udovyk O, Linke S (2015) Science and policy in the governance of Europe's marine environment - the impact of Europeanization, regionalization and the ecosystem approach to management. In: Kern K, Gilek M (eds) Governing Europe's marine environment. Europeanization of regional seas or regionalization of EU policies? Ashgate, Farnham, pp 141-163

Hatchard J, Gray TS (2014) From RACs to advisory councils: lessons from North Sea discourse for the 2014 reform of the European Common Fisheries Policy. Mar Policy 47:87-93 
Hawkins AD (2007) Review of science and stakeholder involvement in the production of advice on fisheries management. Work Package 4 paper of the EU project "Scientific Advice for Fisheries Management at Multiple Scales" (SAFMAMS). Available from: http://www.ifm.dk/ safmams/Downloads/WP3/D2\%20Review\%20of\%20Science\%20and\%20Stakeholder\%20 Involvement.pdf

Hegland TJ (2009) The Common Fisheries Policy and competing perspectives on integration, Publication Series Department of Development and Planning. Aalborg University, Aalborg

Hegland TJ (2012) Fishing for change in EU governance: excursions into the evolution of the Common Fisheries Policy. PhD thesis, Aalborg University, Aalborg

Hegland TJ, Ounanian K, Raakjer J (2012) Why and how to regionalise the Common Fisheries Policy. Marit Stud 11(7)

Hegland TJ, Raakjaer J, van Tatenhove J (2015) Implementing ecosystem-based marine management as a process of regionalisation: some lessons from the Baltic Sea. Ocean Coast Manag (In press)

Howarth W (2008) The interpretation of 'precaution' in the European Community Common Fisheries Policy. J Environ Law 20:213-244

ICES WGMARS Report (2013) Interim report of the Working Group on Maritim Systems (WGMARS), 4-8 Nov 2013, Stockholm, Sweden. ICES CM 2013/SSGSUE:06.30pp

Johannesen O, Lassen H (2014) Decision-making management procedures. Cost - efficiency democracy in selected procedures in maritime spatial planning. TemaNord 2014:532

Lassen H (2009) Scientific advice for Fisheries Management. In Fisheries, sustainability and development. Royal Swedish Academy of Agriculture and Forestry, Stockholm

Lassen H, Kelly C, Sissenwine M (2014) ICES advisory framework 1977-2012: from Fmax to precautionary approach and beyond. ICES J Mar Sci 71:166-172

Linke S, Bruckmeier K (2015) Co-management in fisheries - experiences and changing approaches in Europe. Ocean Coast Manag 104:170-181

Linke S, Jentoft S (2013) A communicative turnaround: shifting the burden of proof in European fisheries governance. Mar Policy 38:337-345

Linke S, Jentoft S (2014) Exploring the phronetic dimension of stakeholders' knowledge in EU fisheries governance. Mar Policy 47:153-161

Linke S, Dreyer M, Sellke P (2011) The regional advisory councils. What is their potential to incorporate stakeholder knowledge into fisheries governance? AMBIO 40(2):133-144

Linke S, Gilek M, Karlsson M, Udovyk O (2014) Unravelling science-policy interactions in environmental risk governance of the Baltic Sea: comparing fisheries and eutrophication. J Risk Res 17(4):505-523

Long R (2010) The role of Regional Advisory Councils in the European Common Fisheries Policy: legal constraints and future options. Int J Mar Coast Law 25:289-346

Mc Goodwin JR (1990) Crisis in the world's fisheries: people, problems, and policies. Stanford California University Press, Stanford

McLeod KL, Leslie H (eds) (2009) Ecosystem-based management for the oceans. Island Press, Washington, DC

Meyer U, Schulz-Schaeffer I (2006) Three forms of interpretative flexibility. In: Science, technology \& innovation studies, Special Issue 1

Möllmann C, Lindegren M, Bleckner T, Bergström L, Casini M, Diekmann R, Flinkman J, MüllerKarulis B, Neuenfeldt S, Schmidt JO, Tomczak M, Voss R, Gårdmark A (2014) Implementing ecosystem-based fisheries management: from single-species to integrated ecosystem assessment and advice for Baltic Sea fish stocks. ICES J Mar Sci 71(5):1187-1197. doi:10.1093/ icesjms/fst123

Nielsen KN, Holm P, Aschan M (2015) Results based management in fisheries: delegating responsibility to resource users. Mar Policy 51:442-451

Österblom H, Hansson S, Larsson U, Hjerne O, Wulff F, Elmgren R, Folke C (2007) Humaninduced trophic cascades and ecological regime shifts in the Baltic Sea. Ecosystems 10:877-889 
Patterson K, Résimont M (2007) Change and stability in landings: the responses of fisheries to scientific advice and TACs. ICES J Mar Sci 64(4):714-717

Punt AE, Smith ADM (2001) The gospel of maximum sustainable yield in fisheries' management: birth, crucifixion and reincarnation. In: Conservation of exploited species, Cambridge University Press, Cambridge

Raakjær J, Hegland TJ (2012) Introduction. Regionalising the Common Fisheries Policy. Marit Stud 11:5

Raakjaer J, Tatenhove J (2014) Marine governance of European seas. Mar Policy 50(Part B):323-382

Renn O (2008) Risk governance: coping with uncertainty in a complex world. Earthscan, London

Rice JC (2005) Implementation of the ecosystem approach to fisheries management - asynchronous co-evolution at the interface between science and policy. Mar Ecol Prog Ser 300:265-270

Salomon M, Markus T, Dross M (2014) Masterstroke or paper tiger - the reform of the EU's Common Fisheries Policy. Mar Policy 47:76-84

Sellke P, Renn O (2010) Risk, society and environmental policy: risk governance in a complex world. In: Gross M, Heinrichs H (eds) Environmental sociology: European perspectives and interdisciplinary challenges. Springer, Dordrecht, pp 295-323

Stange K, Olsson P, Österblom H (2012) Managing organizational change in an international scientific network: a study of ICES reform processes. Mar Policy 36:681-688

Stokstad E (2009) Détente in the fisheries war. Science 324:170-171

Symes D (1997) The European community's common fisheries policy. Ocean Coast Manag 35(2-3):137-155

Symes D (2012) Regionalising the Common Fisheries Policy: context, content and controversies. Marit Stud 11(6)

Urquhart J, Acott T, Symes D, Zhao M (eds) (2014) Social issues in sustainable fisheries management. Springer, Dordrecht

Villasante, LS (2011) Relations between the economy, co-adaptability and resilience of marine ecosystems. Revista Galega de Economia, University of Santiago de Compostela. Faculty of Economics and Business, vol 20(2)

WGIAB (2014) Second interim report of the ICES/HELCOM Working Group on Integrated Assessments of the Baltic Sea. ICES CM 2014/SSGRSP:06

Wilson DC (2009) The paradoxes of transparency. Science and the ecosystem approach to fisheries management in Europe. Amsterdam University Press, Amsterdam

Wilson DC, Delaney AE (2005) Scientific knowledge and participation in the governance of fisheries in the North Sea. In: Gray T (ed) Participation in fisheries governance. Kluwer Academic Publishers, Dordrecht

WKRISCO (2014) Report to ICES ACOM/SCICOM Committee. ICES CM SSGBENCH:01.

Worm B, Hilborn R, Baum JA et al (2009) Rebuilding global fisheries. Science 325:578-585 